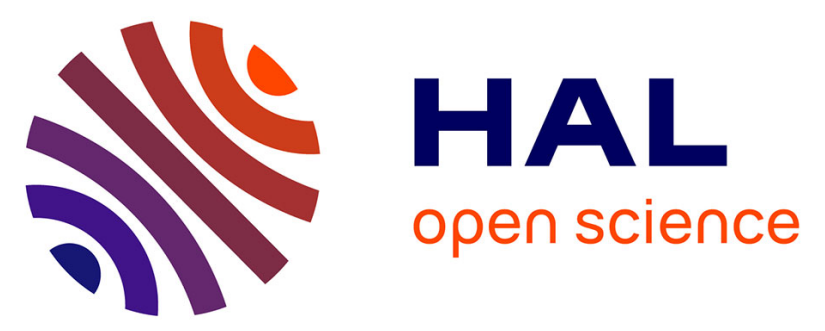

\title{
Association between prophylactic angiotensin-converting enzyme inhibitors and overall survival in Duchenne muscular dystrophy-analysis of registry data
}

Raphaël Porcher, Isabelle Desguerre, Helge Amthor, Brigitte Chabrol, Frédérique Audic, Francois Rivier, Arnaud Isapof, Vincent Tiffreau, Emmanuelle Campana-Salort, France Leturcq, et al.

\section{To cite this version:}

Raphaël Porcher, Isabelle Desguerre, Helge Amthor, Brigitte Chabrol, Frédérique Audic, et al.. Association between prophylactic angiotensin-converting enzyme inhibitors and overall survival in Duchenne muscular dystrophy-analysis of registry data. European Heart Journal, 2021, 10.1093/eurheartj/ehab054 . hal-03179750

\author{
HAL Id: hal-03179750 \\ https://hal.science/hal-03179750
}

Submitted on 25 Mar 2021

HAL is a multi-disciplinary open access archive for the deposit and dissemination of scientific research documents, whether they are published or not. The documents may come from teaching and research institutions in France or abroad, or from public or private research centers.
L'archive ouverte pluridisciplinaire $\mathbf{H A L}$, est destinée au dépôt et à la diffusion de documents scientifiques de niveau recherche, publiés ou non, émanant des établissements d'enseignement et de recherche français ou étrangers, des laboratoires publics ou privés. 


\section{Association between prophylactic}

\section{angiotensin-converting enzyme inhibitors}

\section{and overall survival in Duchenne muscular}

dystrophy-analysis of registry data

Raphaël Porcher ,' Isabelle Desguerre, ${ }^{2}$ Helge Amthor, ${ }^{3}$ Brigitte Chabrol, ${ }^{4}$ Frédérique Audic, ${ }^{5}$ François Rivier, ${ }^{6,7}$ Arnaud Isapof, ${ }^{8}$ Vincent Tiffreau, ${ }^{9}$ Emmanuelle Campana-Salort $\quad,{ }^{10}$ France Leturcq, ${ }^{11}$ Sylvie Tuffery-Giraud Rabah Ben Yaou, ${ }^{13,14}$ Djillali Annane , 15 Pascal Amédro, ${ }^{7,16}$ Christine Barnerias, ${ }^{2}$ Henri Marc Bécane, ${ }^{14}$ Anthony Béhin, ${ }^{14}$ Damien Bonnet $\quad{ }^{17}$ Guillaume Bassez, ${ }^{14}$ Mireille Cossée, ${ }^{12}$ Grégoire de La Villéon, ${ }^{16}$ Claire Delcourte, ${ }^{18}$ Abdallah Fayssoil,${ }^{14,19}$ Bertand Fontaine $\quad{ }^{20}$ François Godart, ${ }^{21}$ Sophie Guillaumont, ${ }^{16}$ Emmanuelle Jaillette, ${ }^{22}$ Pascal Laforêt, ${ }^{19}$ Sarah Leonard-Louis, ${ }^{14}$ Frederic Lofaso, ${ }^{23}$ Michele Mayer, ${ }^{8}$ Raul Juntas Morales, ${ }^{20}$ Christophe Meune ,24 David Orlikowski ,25 Caroline Ovaert ,26 Hélène Prigent, ${ }^{27}$ Malika Saadi, ${ }^{28}$ Maximilien Sochala, ${ }^{28}$ Celine Tard $\quad{ }^{29}$ Guy Vaksmann , ${ }^{29}$ Ulrike Walther-Louvier, ${ }^{6}$ Bruno Eymard, ${ }^{13}$ Tanya Stojkovic , ${ }^{13}$ Philippe Ravaud, ${ }^{1}$ Denis Duboc, ${ }^{28}$ and Karim Wahbi ${ }^{28,30, *}$

${ }^{1}$ Université de Paris, CRESS UMR1153, INSERM, INRA, F-75004, Paris, France; Centre d'Epidémiologie Clinique, AP-HP, Hôtel-Dieu, F-75004 Paris, France; ${ }^{2}$ AP-HP, Centre de Référence des Maladies Neuromusculaires Nord/Est/le de France, Service de Neurologie Pédiatrique, Hôpital Necker, GH Necker-Enfants Malades, Paris, France; ${ }^{3}$ Versailles Saint-Quentin-en-Yvelines University, INSERM U1179, LIA BAHN CSM, Montigny-le-Bretonneux, 78180, Neuromuscular Reference Centre, Paediatric Department, University Hospital Raymond Poincaré, Garches, 92380, France; ${ }^{4}$ Hôpital Timone Enfants, Marseille, France; ${ }^{5}$ Centre de Référence des Maladies Neuromusculaires Nord/Est/lle de France, Service de Neuropédiatrie, Hôpital Roger Salengro, CHRU Lille, Lille, France; ${ }^{6}$ Department of Paediatric Neurology \& Reference Centre for Neuromuscular Diseases AOC, CHU Montpellier, France; ${ }^{7}$ PhyMedExp, University of Montpellier, INSERM, CNRS, Montpellier, France; ${ }^{8}$ Centre de Référence des Maladies Neuromusculaires Nord/Est/lle de France, Service de Neuropédiatrie, Hôpital Trousseau, Paris, France; ${ }^{9}$ Physical and Rehabilitation Medicine Unit, University Hospital, Lille, France, URePSSS (Pluridisciplinary Research Unit: Sports, Health, Society) EA, 7369, Lille University; ${ }^{10}$ APHM, Department of Neurology, Neuromuscular and ALS Reference Centre, La Timone University Hospital, Marseille, France Aix Marseille Université, INSERM, GMGF, Marseille, France; ${ }^{11}$ Laboratoire de Biochimie et Génétique Moléculaire, Hôpital Cochin et Institut de Myologie, Groupe Hospitalier La Pitié Salpétrière, APHP, France; ${ }^{12}$ Laboratory of Genetics of Rare Diseases (LGMR), University of Montpellier, Montpellier, France; ${ }^{13}$ Sorbonne Universités, INSERM UMRS 974, CNRS, UMR-7215, Centre for Research in Myology, Institut de Myologie, Pitié-Salpêtrière University Hospital, Paris, France; ${ }^{14}$ APHP, Centre de Référence de Pathologie Neuromusculaire Paris-Est, FILNEMUS, Myology Institute, Neurology Department, Pitié-Salpêtrière Hospital, Paris, France; ${ }^{15}$ General Intensive Care Unit, Raymond Poincaré Hospital (AP-HP), Lab Inflammation \& Infection, U1173 University Paris Saclay-UVSQ/INSERM, Garches, France; ${ }^{16}$ Paediatric Cardiology, CHU Montpellier, France; ${ }^{17} \mathrm{AP}-\mathrm{HP}$, Unité Médico-Chirurgicale de Cardiologie Congénitale et Pédiatrique, Centre de Référence des Malformations Cardiaques Congénitales Complexes-M3C, Hôpital Necker Enfants Malades, Université Paris Descartes, Sorbonne Paris-Cité, Paris, France; ${ }^{18}$ Critical Care Centre, University Hospital of Lille, Lille Cedex, France; ${ }^{19}$ APHP, Hôpital Raymond Poincaré, Centre de Référence des Maladies Neuromusculaires Nord-Est-l̂le de France, Garches, France; ${ }^{20}$ Department of Neurology \& Reference Centre for Neuromuscular Diseases AOC, CHU Montpellier, France; ${ }^{21}$ Pediatric Cardiology Department, Lille University Hospital, University Nord de France, Lille, France; ${ }^{22}$ Intensive Care Unit, CHU de Lille, Lille, France; ${ }^{23}$ Service d'Explorations Fonctionnelles, Hôpital Raymond Poincaré, Garches, France INSERM Université de Versailles Saint Quentin en Yvelines, France; ${ }^{24}$ APHP, Department of Cardiology, Bobigny Hospital, Paris, XIII University, INSERM UMR S-942, Paris, France; ${ }^{25}$ Réanimation Adultes, APHP, Hôpitaux Universitaires Paris lle de France Ouest, site R. Poincaré, Garches, France; CIC1429 INSERM AP-HP, Hôpitaux Universitaires Paris lle de France Ouest, site R. Poincaré, Garches, France; ${ }^{26}$ Pediatric and Congenital Cardiology, M3C Regional Reference CHD Centre, University Hospital, Marseille Medical Genetics, INSERM UMR 1251 , Aix Marseille University, Marseille, France; ${ }^{27}$ Réanimation adultes, APHP, Hôpitaux Universitaires Paris lle de France Ouest, site R. Poincaré, Garches, France; ${ }^{28}$ APHP, Cochin 
Hospital, Cardiology Department, FILNEMUS, Paris-Descartes, Sorbonne Paris Cité University, Paris, France; ${ }^{29}$ Unité de Cardiologie Congénitale, Hôpital Privé de La Louvière, Lille, France; and ${ }^{30}$ INSERM Unit 970, Paris Cardiovascular Research Centre (PARCC), Paris, France

Aims To estimate the effect of prophylactic angiotensin-converting enzyme inhibitors (ACEi) on survival in Duchenne muscular dystrophy (DMD).

\section{Methods}

and results
We analysed the data from the French multicentre DMD Heart Registry (ClinicalTrials.gov: NCT03443115). We estimated the association between the prophylactic prescription of ACEi and event-free survival in 668 patients aged 8 to 13 years, with normal left ventricular function, using (i) a Cox model with intervention as a timedependent covariate, (ii) a propensity-based analysis comparing ACEi treatment vs. no treatment, and (iii) a set of sensitivity analyses. The study outcomes were overall survival and hospitalizations for heart failure (HF) or acute respiratory failure. Among the 668 patients included in the DMD Heart Registry, 576 (mean age $6.1 \pm 2.8$ years) were eligible for this study, of whom 390 were treated with ACEi prophylactically. Death occurred in 53 patients (13.5\%) who were and 60 patients (32.3\%) who were not treated prophylactically with ACEi, respectively. In a Cox model with intervention as a time-dependent variable, the hazard ratio $(H R)$ associated with $A C E i$ treatment was 0.49 [95\% confidence interval $(\mathrm{Cl}) 0.34-0.72$ ] and $0.47(95 \% \mathrm{Cl} 0.31-0.17)$ for overall mortality after adjustment for baseline variables. In the propensity-based analysis, 278 patients were included in the treatment group and 834 in the control group, with $18.5 \%$ and $30.4 \% 12$-year estimated probability of death, respectively. ACEi were associated with a lower risk of death (HR 0.39; 95\% Cl 0.17-0.92) and hospitalization for HF (HR 0.16; $95 \%$ $\mathrm{Cl} 0.04-0.62$ ). All other sensitivity analyses yielded similar results.

Prophylactic ACEi treatment in DMD was associated with a significantly higher overall survival and lower rates of hospitalization for HF.

\section{Graphical Abstract}

\section{French multicentre DMD-Heart-Registry ( $n=668$ patients)}

Propensity-based analysis comparing ACE inhibitor treatment versus no treatment in patients with normal left ventricular function, between the ages of 8 and 13 years

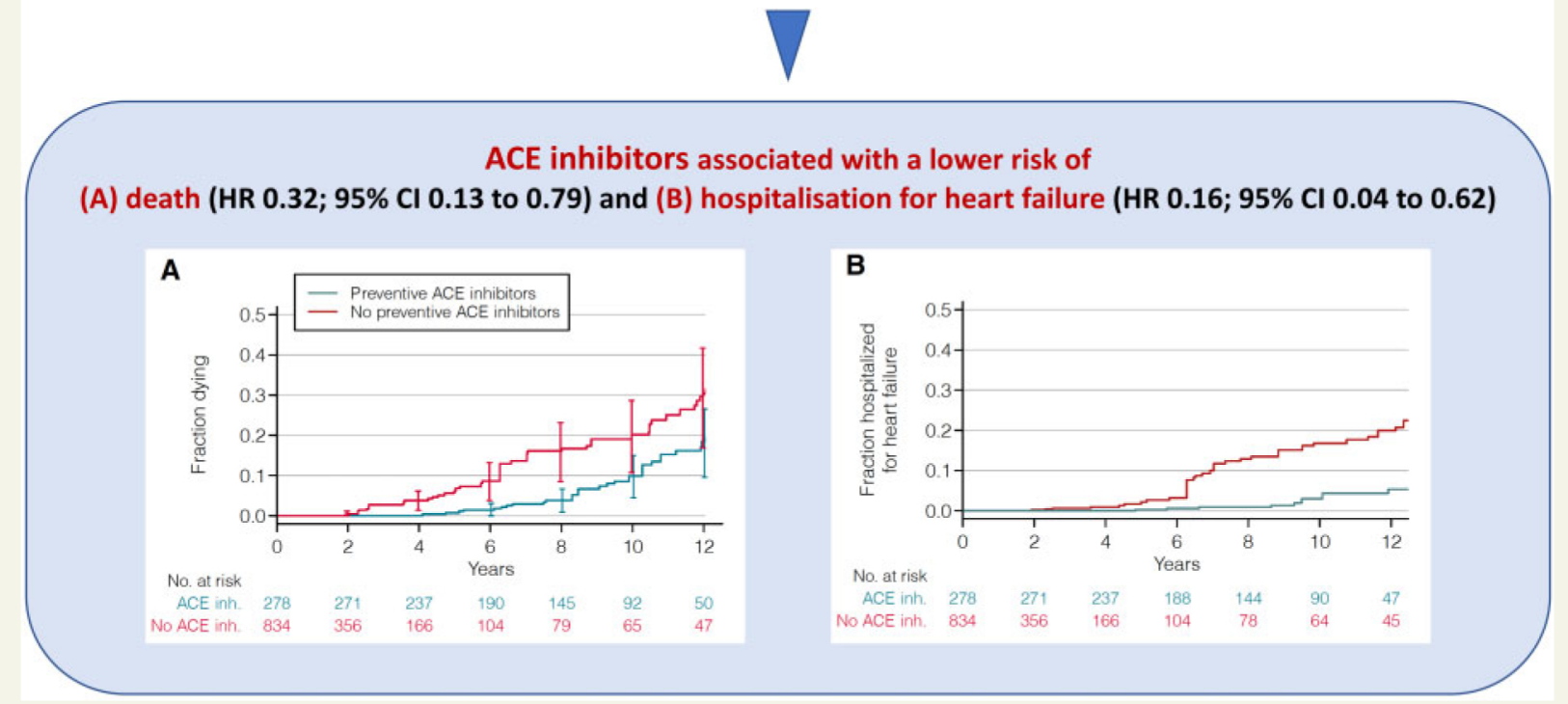

Association between prophylactic angiotensin-converting enzyme inhibitors and overall survival in Duchenne muscular distrophy. 


\section{Introduction}

Duchenne muscular dystrophy (DMD) is an X-linked genetic disorder that affects approximately 1 in every 3500 live-born male infants, making it the most common neuromuscular disease of childhood. ${ }^{1}$ The disease is caused by mutations in the dystrophin gene (DMD), which lead to disruption of the open reading frame $e^{2,3}$ and dystrophin deficiency in muscle cells, resulting in decreased fibre stability and continued degeneration. ${ }^{4}$ The patients present with progressive muscle wasting and loss of muscle function, develop restrictive respiratory failure and dilated cardiomyopathy, and usually die in their late teens or twenties from cardiac or respiratory failure. $^{5,6}$

To delay the onset of cardiomyopathy, the majority of experts recommend the use of angiotensin-converting enzyme inhibitors (ACEi) in DMD patients by the age of 10 years, even in the presence of preserved left ventricular (LV) systolic function. ${ }^{7-13}$ A survival benefit conferred by this treatment has been suggested by a single randomized open-label trial, though this remains uncertain. ${ }^{14}$ Prophylactic ACEi are prescribed to the majority of patients in most neuromuscular referral centres; however, this strategy is not offered to most DMD patients anywhere else, including the USA. ${ }^{15,16}$

In a clinical environment where randomized trials are precluded by practical and ethical reasons, ${ }^{17,18}$ we decided to perform a propensity-based analysis, using data from a large French multicentre DMD registry, to evaluate the effect of ACEi on overall survival.

\section{Methods}

The data, analytic methods, and study materials are not being made available to other researchers for the purposes of reproducing the results or replicating the procedure, because consent to participate in this study did not include public dissemination of patient data.

\section{Patients}

The patients included in this retrospective study were identified among the 668 patients entered in the DMD Heart Registry. This registry comprises patients who had been admitted between January 1986 and October 2018 to one of eight French medical centres for management of DMD (Cochin Hospital, Paris; Lille Hospital; Marseille Hospital; Montpellier Hospital; Necker Hospital, Paris; Pitié Salpêtrière Hospital, Paris; Raymond Poincaré Hospital, Garches; Trousseau Hospital, Paris) and fulfilled the following criteria: (i) a clinical profile consistent with a diagnosis of DMD; (ii) a mutation in the DMD gene, causing disruption of the reading frame or generation of a premature stop codon (verified in one of two specialized centres for DMD gene sequencing in France-Cochin Hospital and Montpellier University Hospital). The patients' medical records were reviewed and the following information was collected: results of genetic, neurological, and cardiac investigations; cardiovascular and respiratory events; drug treatments, doses, side effects; and dates and reasons for initiation, titration, or interruption of treatments.

Of the 668 patients included in the DMD Heart Registry, we excluded those (i) who had been diagnosed with DMD before January 1986, corresponding to prevalent cases; (ii) who had a concurrent illness that could also cause cardiac or respiratory disease or influence the vital prognosis; or (iii) whose date of treatment initiation was unknown. The remaining patients were eligible for the present study.

This study complied with the ethical principles set out in the declaration of Helsinki. The local ethics committees approved the study and granted waiver of participant consent. The study was registered at ClinicalTrials.gov (NCT03443115).

\section{Study outcomes}

The primary study outcome was overall survival. Secondary outcomes were hospitalizations for heart failure $(\mathrm{HF})^{19}$ and acute respiratory failure (ARF) during follow-up. We ascertained the survival of patients who were not followed beyond December 2016 by consulting the National Death Registry. An adjudication committee unaware of the patients' clinical status or outcomes, composed of three of the authors (KW, PL, AF), reviewed the data and classified the hospitalizations as HF- or ARFrelated, according to pre-specified critধ

\section{Statistical analysis}

Results are shown as means \pm standard deviation, median and interquartile range (IQR), or counts and percentages, as appropriate. We estimated the overall survival curves and the cumulative incidence curves for hospitalization for $\mathrm{HF}$ and ARF.

In a first analysis, the effect of ACEi was estimated in a Cox model, with the introduction of prophylactic ACEi treatment as a timedependent variable, without and with adjustment for baseline variables, including age, LV ejection fraction (LVEF), vital capacity (VC), systolic and diastolic blood pressure (BP), loss of ambulation, DMD mutation, and centre as a random effect. Glomerular filtration rate was not included in this model because its estimation is not currently performed in a routine setting. ${ }^{20}$ This analysis has been shown to inappropriately correct for time-dependent confounding, ${ }^{21}$ though it is considered a standard approach for comparisons.

We then performed a propensity-based analysis and emulated a target trial with the inclusion of patients who fulfilled the following inclusion criteria: (i) age between 8 and 13 years, (ii) no previous ACEi treatment, and (iii) LVEF $\geq 55 \%$, between January 1999 to December 2016. The inclusion process is illustrated in Figure 1 :

We divided the overall inclusion period, from January $1999^{-}$to December 2016, into 72 consecutive, 3-month periods, ${ }^{22-26}$ identified all patients who met the inclusion criteria within each period, and included in the treatment group the patients whose treatment was introduced during that 3-month period. For each treated patient, we entered in a control group a random sample of three untreated patients, simulating a 1:3 randomization scheme, thus comparing patients-periods instead of individual patients, with regard to baseline characteristics and outcomes.

Patients in the control group were eligible for inclusion in the following 3 -month periods, though no patients entered in the treatment group. ${ }^{24,27}$ The process was repeated over the 72 inclusion periods, before pooling all the data. Patients were followed from the date of inclusion to the date of death or until 31 December 2017, whichever occurred first. The date of 31 December 2017 guaranteed at least 1 year of theoretical follow-up for all patients. The follow-up of patients in the control group was censored when they were prescribed an ACEi.

Since treatment groups were not randomly assigned, the inverse probability of treatment weighting was used to correct for confounding by indication. ${ }^{28,29}$ The propensity score, i.e. the probability of receiving $A C E$ i prophylaxis, was estimated by logistic regression with the following covariates: age, LVEF, VC, loss of ambulation, systolic and diastolic BP, non-invasive ventilation, spinal surgery, glucocorticoid and centre as a random effect, all measured at the time of inclusion in 


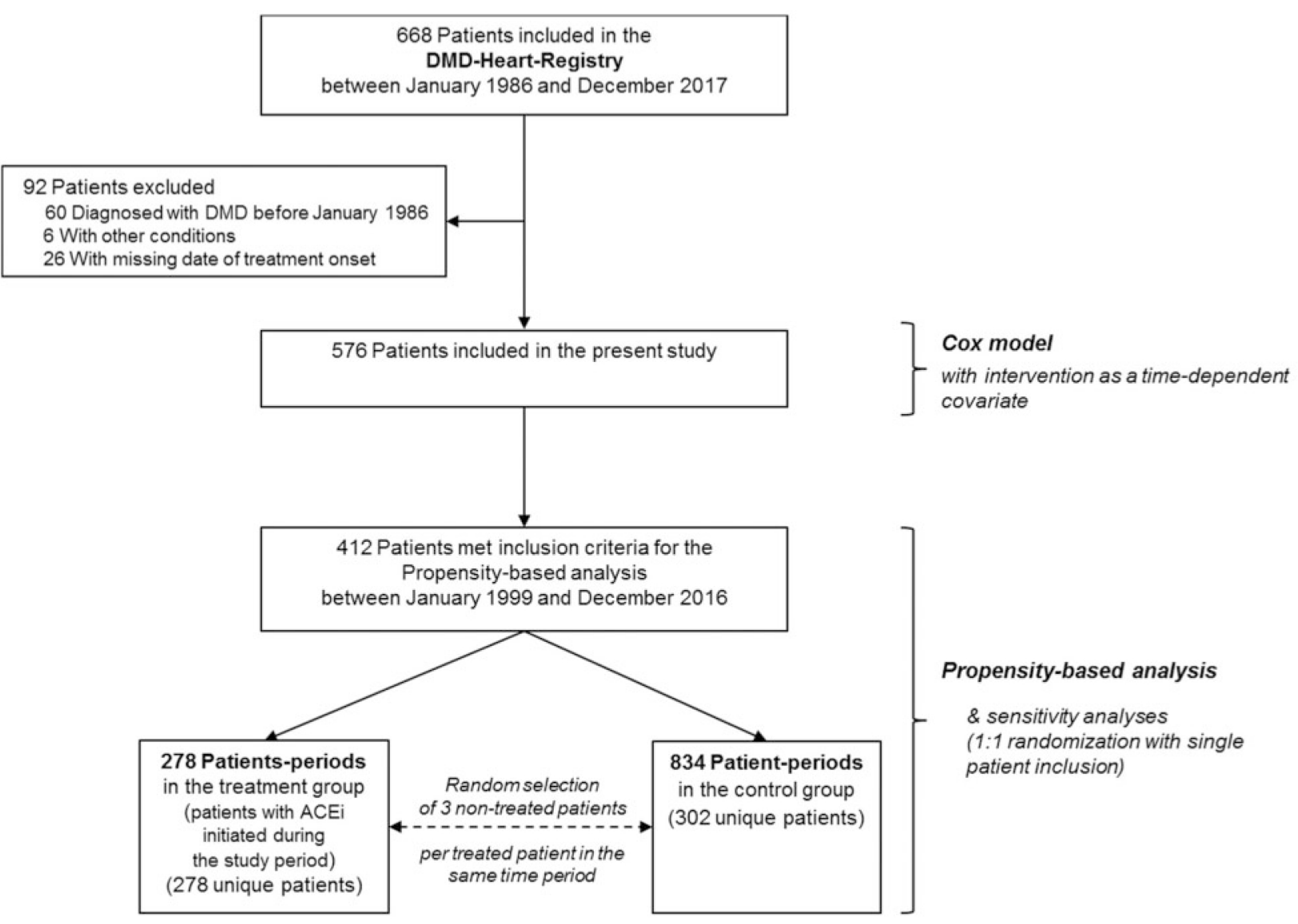

Figure I Patient selection process from the DMD Heart Registry.

the emulated trial. Each observation was weighted by the inverse of the predicted probability of receiving the treatment actually received, given these variables. ${ }^{28,29}$ This has been shown to theoretically balance the groups regarding these confounders. Balance was ascertained by calculating the standardized mean differences between groups before and after weighting; $a<10 \%$ standardized difference was considered to indicate successful balancing. ${ }^{30,31}$ In the control group (no ACEi prophylaxis), patients were arbitrarily censored when they received ACEi prophylaxis, and inverse probability of censoring weighting was used to correct for the induced time-varying selection. ${ }^{32}$ Inverse probability of censoring weights was proportional to the inverse of the probability of remaining uncensored until each timepoint, given the baseline and time-varying covariates. ${ }^{29,33}$ This probability was obtained by fitting a Cox model with age at inclusion in the emulated trial and centre as a time-fixed covariate, and with LVEF, VC, loss of ambulation, systolic and diastolic BP, non-invasive ventilation, spinal surgery, glucocorticoid as time-varying covariates. Stabilized weights, which usually increase the efficiency of estimates, were obtained by multiplying the weights by the overall probability of being uncensored at each timepoint, and the resulting weights were truncated at the first and $99^{\text {th }}$ percentile to limit the influence of outlier observations. ${ }^{34}$ Each observation was then weighted by the product of the inverse probability of treatment and the time-varying inverse probability of censoring weights, and overall survival curves and cumulative incidence curves for hospitalization for HF and ARF were estimated while accounting for these weights. The treatment effect was summarized by the hazard ratio $(H R)$, estimated in a Cox proportional hazards model, with baseline hazard stratified by 3 -month inclusion periods to account for period effects. Standard errors and confidence intervals $(\mathrm{Cl})$ were obtained by bootstrapping. The proportional hazards assumption in Cox models was evaluated by examination of Schoenfeld residuals and Grambsch-Therneau lack-of-fit test.

To use values of LVEF, VC and BP at any arbitrary time while they were recorded at specific irregular timepoints, we used the best linear unbiased predictions obtained from flexible mixed-effect models. ${ }^{35}$

Sensitivity analyses were carried out by repeating the propensitybased analysis, using a 1:1 allocation ratio and including a given individual only once

We also assessed the sensitivity of the results to unmeasured confounding by computing the E-value when a non-null association was reached. The Evalue measures the minimum strength of association needed between an unmeasured confounder and ACEi treatment and outcome, to fully explain the observed treatment effect or the upper confidence limit. ${ }^{36}$ Prespecified subgroup analyses were carried out for the 1:3 propensitybased analysis, according to treatment by glucocorticoids at study entry and inability to walk. 


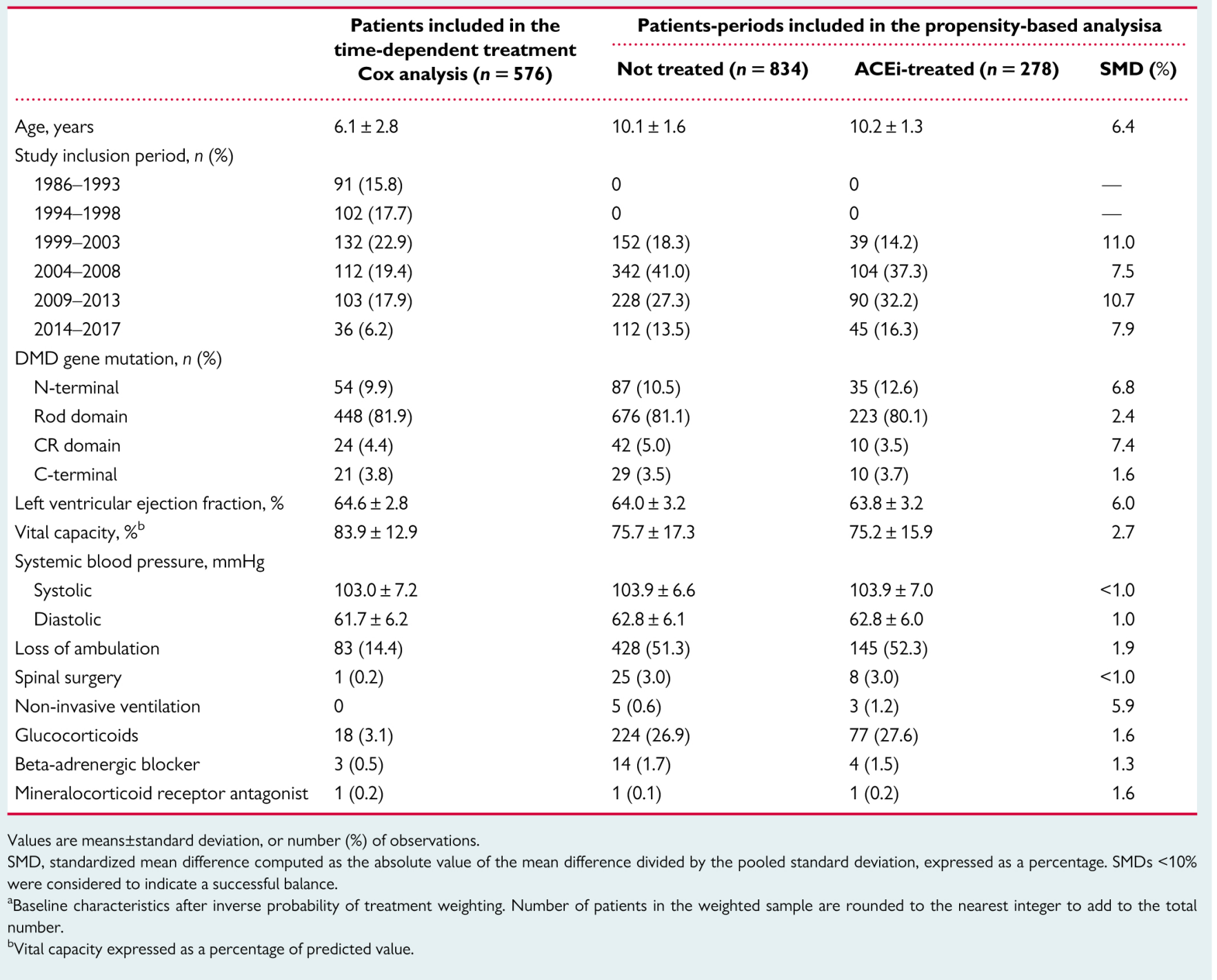

All analyses were performed using R 3.6.3 (The R Foundation for Statistical Computing, Vienna, Austria). A $P$-value $<0.05$ was considered statistically significant.

\section{Results}

\section{Patient selection}

Figure 1 shows the selection of patients included in the present study. Of the 668 patients entered in the DMD Heart Registry between November 1986 and March 2017, 60 were excluded because the diagnosis of DMD was made before January 1986, 26 because the date of treatment initiation was not available, and 6 because they suffered from concomitant disorders. The remaining 576 patients (mean age $6.1 \pm 2.8$ years) were included in this study and were potentially eligible for the propensity-based analysis. Their baseline characteristics are presented in Table 1. The median follow-up was 13.5 years (range 4 months to 30.6 years). ACEi treatment was introduced in 390 patients $(67.7 \%)$ of various ages with LVEF $\geq 55 \%$, after a median treatment-free follow-up of 4.6 years (range 0 to 19.4).
3. The proportion of patients treated with ACEi was $62.5 \%$ at Cochin Hospital, $66.2 \%$ at Lille Hospital, 47.3\% at Marseille Hospital, $60.3 \%$ at Montpellier Hospital, $72.9 \%$ at Necker Hospital, 67.2\% at Pitié-Salpêtrière Hospital, $73.0 \%$ at Raymond Poincaré Hospital, and $88.2 \%$ at Trousseau Hospital.

\section{Patient outcomes}

Among the 390 prophylactically treated patients, 53 died (13.6\%) at a median age of 20.0 years, vs. 60 (32.3\%) at a median age of 21.0 years among the 186 untreated patients (Table 2). Among non-survivors, eight prophylactically treated patients $(15 \%)$ died of $\mathrm{HF}$, in contrast to 23 untreated patients (38\%). ARF was the cause of death in 15 (28\%) ACEi-treated patients and 17 (28\%) untreated patients. Other causes of death were identified in 20 (38\%) ACEi-treated patients and $9(15 \%)$ untreated patients, while no cause of death was recorded in $10(19 \%)$ and $11(18 \%)$ patients, respectively. HF was the cause of hospitalization in 46 patients, 18 of whom were and 28 were not prophylactically treated with ACEi. ARF was the cause of 


\begin{tabular}{|c|c|c|c|c|c|}
\hline & \multicolumn{3}{|c|}{$\begin{array}{l}\text { Patients included in the Cox } \\
\text { model with intervention } \\
\text { as a time-dependent covariate }\end{array}$} & \multicolumn{2}{|c|}{$\begin{array}{l}\text { Patients included in the propensity-based } \\
\text { analysis ( } n=1112 \text { patients-periods, } \\
n=412 \text { unique patients) }\end{array}$} \\
\hline & $\begin{array}{l}\text { All patients } \\
(n=576)\end{array}$ & $\begin{array}{l}\text { Not treated } \\
(n=186)\end{array}$ & $\begin{array}{l}\text { ACEi-treated } \\
(n=390)\end{array}$ & $\begin{array}{l}\text { Control group } \\
(n=834)\end{array}$ & $\begin{array}{l}\text { ACEi group } \\
(n=278)\end{array}$ \\
\hline Person-year follow-up & 7662.1 & 4189.0 & 3473.1 & $2164.5^{\mathrm{a}}$ & $2181.0^{\mathrm{a}}$ \\
\hline Deaths & 113 & 60 & 53 & 55 & 29 \\
\hline Hospitalization for heart failure & 46 & 28 & 18 & 31 & 9 \\
\hline Hospitalization for acute respiratory failure & 178 & 76 & 102 & 68 & 67 \\
\hline
\end{tabular}

Weighted person-year follow-up to match with cumulative incidence and HR estimation.

Table 3 Association between angiotensin-converting enzyme inhibitors and the primary and secondary outcomes estimated in a Cox model and a propensity-based analysis

\begin{tabular}{|c|c|c|c|}
\hline & \multicolumn{2}{|c|}{ Cox model with intervention as a time-dependent covariate } & \multirow{2}{*}{$\begin{array}{l}\text { Adjusted HR } \\
\quad(95 \% \mathrm{Cl})\end{array}$} \\
\hline & $\begin{array}{l}\text { Propensity score-based } \\
\text { analysis HR }(95 \% \mathrm{CI})\end{array}$ & $\begin{array}{l}\text { Unadjusted } \\
\text { HR }(95 \% \mathrm{CI})\end{array}$ & \\
\hline Overall survival & $0.49(0.34-0.72)$ & $0.47(0.31-0.71)$ & $0.39(0.17-0.92)$ \\
\hline Hospitalization for heart failure & $0.37(0.20-0.68)$ & $0.50(0.26-0.99)$ & $0.16(0.04-0.62)$ \\
\hline Hospitalization for acute respiratory failure & $0.76(0.56-1.04)$ & $0.98(0.70-1.36)$ & $0.78(0.35-1.72)$ \\
\hline
\end{tabular}

No evidence for non-proportional hazards was found, except for the effect of angiotensin-converting enzyme inhibitors on hospitalization for acute respiratory failure in the propensity-based analysis ( $P=0.031$ for the proportional hazards), which is also displayed in Figure 2 , where the curves of cumulative incidence cross.

hospitalization in 178 patients, 102 of whom were and 76 were not prophylactically treated with ACEi (Table 2).

\section{Cox model with intervention as a time- dependent covariate}

In a model with intervention as a time-dependent variable, the $H R$ for overall mortality associated with the prescription of ACEi after adjustment for baseline variables was 0.49 (95\% $\mathrm{Cl} 0.34-0.72$ ) and 0.47 (95\% Cl 0.31-0.71) in unadjusted and adjusted models, respectively (Table 3). An association was also observed between ACEi treatment and hospitalization for $\mathrm{HF}$ (HR 0.50; 95\% Cl 0.26-0.99), though not between ACEi treatment and ARF (HR 0.98; 95\% Cl 0.70-1.36) (Table 3).

\section{Propensity-based analysis}

Of the 576 eligible patients, 412 met the inclusion criteria (age between 8 and 13 years, no previous ACEi treatment, and LVEF $\geq 55 \%$ ) at least once between January 1999 and December 2016. Of the 164 ineligible patients, 74 did not satisfy the age criterion, 20 received an ACEi before 1999 and 41 before the age of 8 years, and the 29 remaining patients had a LVEF $<55 \%$ before satisfying the other inclusion criteria. Their baseline characteristics are presented in Table 1. Missing variables among those included in this model were VC for 42 patients and BP for 21 patients. The total follow-up for these 412 patients corresponded to 4209 patients-periods, including 278 patients-periods when treated and 3931 when not treated preventively with ACEi.

We included 278 patients in whom ACEi was introduced during the inclusion period in the treatment group and 834 patients-periods untreated with ACEi in the control group (Figure 1). The characteristics of patients-periods included in both groups before and after correction with the inverse probability of treatment weighting are shown

Table 1, respectively. The treated group was slightly older than the control group, had a lower LVEF and VC, and was more likely to have lost ambulation, as well as to have been previously treated with glucocorticoids and undergone spine surgery. The baseline characteristics of patients in the treated (mean age 10.2 \pm 1.3 years) and control (mean age 10.1 \pm 1.6 years) groups were successfully balanced after weighting. In the treatment group, ACEi were discontinued in 5 patients $(1.8 \%)$ because of adverse events, including symptomatic hypotension in $2(0.7 \%)$ and cough in $2(0.7 \%)$; no patient experienced a life-threatening event.

Over a median follow-up of 8.2 years (IQR 5.4-10.8), 29 patients died in the treatment group, and 55 patients died in the control group over a median follow-up of 1.7 year (IQR 0.8-3.4), or 8.1 years (IQR 5.3-10.7) without artificial censoring when treated with ACEi (Table 2), corresponding to $18.5 \%$ and $30.4 \%$ 12-year estimated risk of death, respectively (Figure 2). Preventive treatment with ACEi was associated with a lower risk of death (HR 0.39; 95\% Cl 0.17-0.92) and hospitalization for HF (HR 0.16; 95\% Cl 0.04-0.62), but not with a lower risk of hospitalization for ARF (HR 0.78; 95\% Cl 0.35-1.72), 


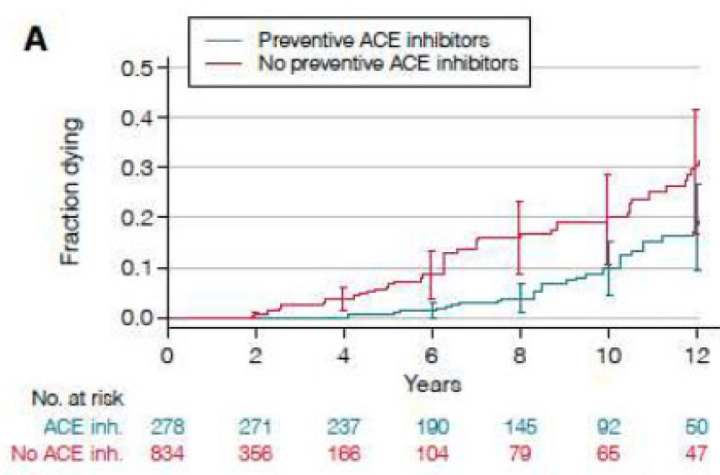

B

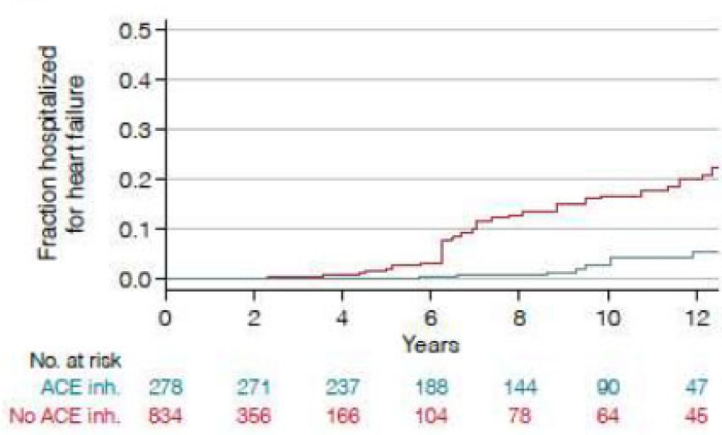

c

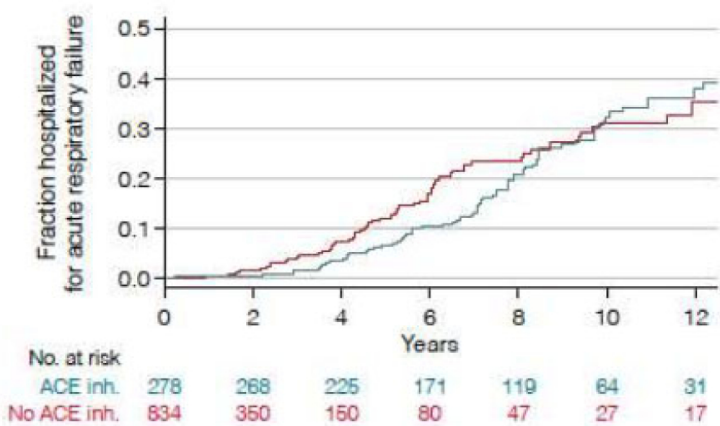

Figure 2 Incidence of primary and secondary outcomes in the propensity-based analysis. (A) All-cause mortality; (B) hospitalization for heart failure; $(C)$ hospitalization for acute respiratory failure.

though there was some evidence of non-proportional hazards for the latter effect ( $P=0.031$; Table 3; Figure 2$)$. There was no evidence of a differential association of preventive treatment with ACEi with death according to glucocorticoid use or loss of ambulation at inclusion (Figure 3).

The E-value for overall survival was 3.22 , indicating that an uncontrolled confounder would need to be associated with both preventive treatment with ACEi and death by a relative effect of 3.22 each to explain the association. The E-value for the $95 \%$ upper confidence bound was 1.17 , so the latter relative association would suffice to make the observed association appear non-significant. The E-values for hospitalization for HF were 12.8 and 2.61 for the estimated and the upper confidence bound, respectively

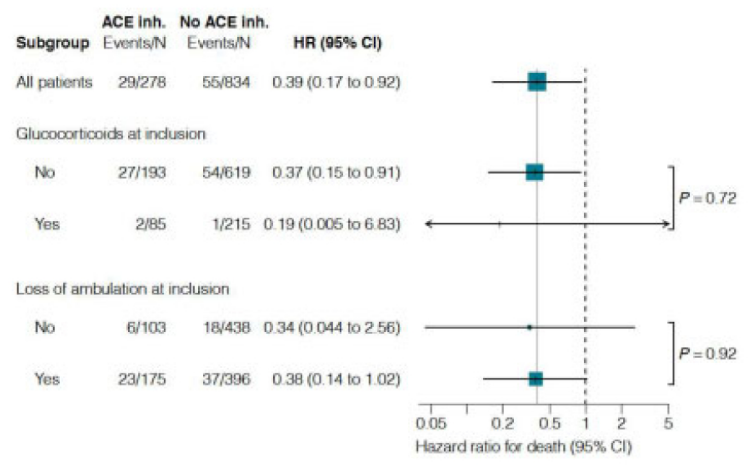

Figure 3 Exploratory subgroup analysis in the propensity-based analysis. HR are for the primary outcome (death). The numbers of events may not closely represent the HR because of the differential follow-up in each group.

All other sensitivity analyses yielded similar results for overall survival, including the propensity-based analysis with a 1:1 allocation ratio and unique inclusion of individuals ( $\mathrm{HR} 0.49 ; 95 \% \mathrm{Cl} 0.24-0.96$ )

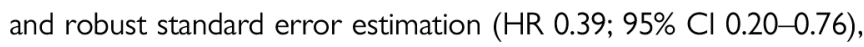
and for the secondary endpoints

\section{Discussion}

This analysis consistently revealed a significant overall survival benefit and lower risk of hospitalization for the management of HF associated with prophylactic ACEi treatment in DMD patients with preserved LV function (Graphical Abstract).

Most prior studies showed that prophylactic ACEi treatment of DMD patients is used mostly in neuromuscular tertiary medical centres, but not in all DMD patients anywhere ${ }^{15,16}$ despite the recommendations by most groups of experts. . $^{17,18,37,38}$ For example, a retrospective study in 17 centres across the USA reported the use of ACEi in $<50 \%$ of DMD patients between 2005 and $2015 .{ }^{15}$ We observed that $67 \%$ of patients included in our study received ACEi prophylactically, with ratios ranging from $60 \%$ to $73 \%$ in six medical centres. This observation highlights the wide variability in the prescription of ACEi not only among medical centres, but also by individual physicians. This variability might be related to the intermediate level of evidence assigned to this treatment for this specific condition, leading to the implementation of general HF guidelines with treatment initiation in the presence of overt systolic dysfunction. In this context, where this treatment has been adopted in clinical practice, though not regularly offered to all patients, a randomized trial with mortality as the endpoint would be unethical as well as impractical because of the long follow-up and large sample size required. In such cases, a propensity-based analysis emulating a randomized trial is particularly useful to estimate a treatment effect in a real-life setting, and to mitigate confounding biases that arise in absence of random assignment. ${ }^{24,27}$ Our large patient sample allowed for the inclusion of all known prognostic factors in DMD in our analysis. Furthermore, our propensity-based analysis enabled a comparison of treated patients 
and controls over the same time periods, which is particularly important in view of the major progress made in recent decades in the standard of care for this disorder. Since the potential for unmeasured confounding persisted, an E-value analysis was undertaken to quantify the minimum strength of association that an unmeasured confounder must have with both ACEi treatment and study outcomes to negate the observed associations, while simultaneously considering the measured covariates. We found that a residual confounding could explain the association if an unmeasured covariate exists that has $a \geq 3.78$ relative risk association with total mortality and $\geq 12.0$ with hospitalizations for HF, which seems unlikely in this setting. The magnitude of the prophylactic treatment effect of ACEi in this study is consistent with that observed in the only randomized study conducted to date in 57 patients suffering from DMD. In that study, the 10 -year survival rates were $93 \%$ vs. $66 \%$ in patients randomly assigned to 3 years of perindopril vs. placebo, corresponding to an odds ratio of 0.15 . $^{14}$

As the clinical management of patients with DMD is heterogeneous, ${ }^{15,16}$ a propensity score analysis seems more likely to yield results that can be generalized than a randomized trial. Despite being based on observational data, our emulated trial was similar to a randomized, controlled target trial including, in particular, clear eligibility criteria. Confounding and time-varying selection biases were corrected by inverse probability weighting, and the design of the emulated trial prevented the introduction of immortal time biases. ${ }^{27}$ In particular, the shorter follow-up of the control group, explained by artificial censoring at initiation of prophylactic treatment with ACEi, was corrected by inverse probability of censoring weighting. No intention-to-treat analysis was considered because of the high number of patients who received ACEi at some point during follow-up. Instead, patients who were prophylactically treated with ACEi were compared with patients who remained untreated. This is different from a per-protocol analysis, as patients in the treatment group who discontinued treatment for any reason (perhaps for toxicity) remained in that group, revealing treatment effects closer to real life.

In natural history studies, end-stage HF developed in up to $40 \%$ of DMD patients in the second or third decades of life, ${ }^{17,37}$ providing a strong impetus for the first randomized study of the prophylactic use of ACEi in this population, earlier than usually prescribed for dilated cardiomyopathy. A single, open-label, randomized trial in 57 patients revealed a lower incidence of dilated cardiomyopathy in patients aged 9 to 13 years treated prophylactically with perindopril compared with placebo, and suggested a higher survival at 10 years. ${ }^{14}$ The prevention of severe HF and higher overall survival observed in our study strongly support the widespread use of this treatment strategy in DMD patients, especially because its tolerance was excellent. In a broader perspective, these results suggest that HF treatments may be beneficial not only in patients with LV systolic dysfunction, but also at earlier stages of the disease characterized by malignant and progressive myocardial involvement, in order to delay the development of severe HF.

\section{Study limitations}

The main limitation of this study was the estimation of an association of prophylactic use of ACEi with outcomes, based on non-random assignments. However, the likelihood of differences exclusively due to biases was limited by (i) the magnitude of the effect observed, (ii) the consistency of our results, and (iii) the application of the most effective methods of adjustment for selection biases and confounding factors. Another limitation was the absence of accounting for drug doses in our analysis of treatment efficacy. Finally, we allowed a 3month grace period to classify the participants in the ACEi group, which may have created an immortal time bias. We could have (i) duplicated the participants and censored them if they deviated from the original assignment, or (ii) randomly assigned them to one of the study groups. ${ }^{22,39,40}$ However, given that a single patient was followed for $<3$ months and no event occurred during that follow-up, this had no practical effect on the results.

Emulating a target trial is, nevertheless, a complex task, and several statistical tools were used, which rely on assumptions. In particular, we had to assume that all relevant confounders were measured repeatedly during follow-up. Despite being cautious in our recording of prognostic variables, we cannot exclude having overlooked confounders. In addition, since physiological measurements were not made every 3 months, we predicted their values by modelling. Our analyses, therefore, rely on a sufficient accuracy of these predictions, as well as on a reasonable specification of the propensity score and censoring models. We believe, nevertheless, that a complex and imperfect emulated trial approach remains the most sensible means of obtaining reliable information on the potential effect of ACEi prophylaxis in this context, where large trials are not likely to be conducted. It also provides results emulating more traditional studies, despite time-varying treatments and confounding. Finally, it clearly defined the target population, in contrast with other modelling techniques, such as the Cox model with time-dependent variables that we used for comparison, where precise eligibility criteria that may change over time cannot be applied.

\section{Conclusions}

A significantly higher overall survival and lower rates of hospitalization for HF were observed with the prophylactic prescription of ACEi than without treatment in patients presenting with DMD and a preserved LV function.

\section{Acknowledgements}

Rodolphe Ruffy, MD, FACC reviewed the article for style and language.

\section{Funding}

This work was supported by grants from the Association Monégasque contre les Myopathies (Onlywatch Charity Auction), which was involved in neither the design and conduct of the study, the collection, management, analysis, and interpretation of the data, preparation, review or approval of the manuscript, nor the decision to submit the article for publication.

Conflict of interest: none declared. 


\section{References}

1. Emery AE. Population frequencies of inherited neuromuscular diseases - a world survey. Neuromuscul Disord 1991;1:19-29.

2. Aartsma-Rus A, Van Deutekom JC, Fokkema IF, Van Ommen GJ, Den Dunnen JT. Entries in the Leiden Duchenne muscular dystrophy mutation database: an overview of mutation types and paradoxical cases that confirm the readingframe rule. Muscle Nerve 2006;34:135-144.

3. Muntoni F, Torelli S, Ferlini A. Dystrophin and mutations: one gene, several proteins, multiple phenotypes. Lancet Neurol 2003;2:731-740.

4. Hoffman EP, Fischbeck KH, Brown RH, Johnson M, Medori R, Loire JD, Harris JB, Waterston R, Brooke M, Specht L, Kupsky W, Chamberlain J, Caskey CT, Shapiro F, Kunkel LM. Characterization of dystrophin in muscle-biopsy specimens from patients with Duchenne's or Becker's muscular dystrophy. N Engl J Med 1988;318:1363-1368.

5. Emery AE. The muscular dystrophies. Lancet 2002;359:687-695.

6. Emery A, Muntoni F, Duchenne Muscular Dystrophy. 3rd ed. New York: Oxford University Press; 2003.

7. Duboc D, Meune C, Lerebours G, Devaux JY, Vaksmann G, Bécane HM. Effect of perindopril on the onset and progression of left ventricular dysfunction in Duchenne muscular dystrophy. J Am Coll Cardiol 2005;45:855-857.

8. Barber BJ, Andrews JG, Lu Z, West NA, Meaney FJ, Price ET, Gray A, Sheehan DW, Pandya S, Yang M, Cunniff C. Oral corticosteroids and onset of cardiomyopathy in Duchenne muscular dystrophy. J Pediatr 2013;163:1080-1084.

9. Houde S, Filiatrault M, Fournier A, Dubé J, D’Arcy S, Bérubé D, Brousseau Y, Lapierre G, Vanasse M. Deflazacort use in Duchenne muscular dystrophy: an 8year follow-up. Pediatr Neurol 2008;38:200-206.

10. Silversides CK, Webb GD, Harris VA, Biggar DW. Effects of deflazacort on left ventricular function in patients with Duchenne muscular dystrophy. Am J Cardiol 2003;91:769-772

11. Biggar WD, Harris VA, Eliasoph L, Alman B. Long-term benefits of deflazacort treatment for boys with Duchenne muscular dystrophy in their second decade. Neuromuscul Disord 2006;16:249-255.

12. Markham LW, Kinnett K, Wong BL, Woodrow Benson D, Cripe LH. Corticosteroid treatment retards development of ventricular dysfunction in Duchenne muscular dystrophy. Neuromuscul Disord 2008;18:365-370.

13. Mavrogeni S, Papavasiliou A, Douskou M, Kolovou G, Papadopoulou E, Cokkinos DV. Effect of deflazacort on cardiac and sternocleidomastoid muscles in Duchenne muscular dystrophy: a magnetic resonance imaging study. Eur J Paediatr Neurol 2009;13:34-40.

14. Duboc D, Meune C, Pierre B, Wahbi K, Eymard B, Toutain A, Berard C, Vaksmann G, Weber S, Bécane HM. Perindopril preventive treatment on mortality in Duchenne muscular dystrophy: 10 years' follow-up. Am Heart J 2007;154 596-602.

15. Lal AK, Wittlieb-Weber CA, Villa CR, Cunningham C, Bock MJ, Gambetta KE, Johnson JN, Schumacher KR, Law SP, Deshpande SR, West SC, Friedland-Little JM, Lytrivi ID, McCulloch MA, Ou Z, Presson AP, Butts RJ. Utilization of heart failure medications in Duchenne muscular dystrophy patients with left ventricular systolic dysfunction [abstract. J Heart Lung Transplant 2019;38 Suppl: S466].

16. Cowen L, Mancini M, Martin A, Lucas A, Donovan JM. Variability and trends in corticosteroid use by male United States participants with Duchenne muscular dystrophy in the Duchenne Registry. BMC Neurol 2019;19:84.

17. Birnkrant DJ, Bushby K, Bann CM, Alman BA, Apkon SD, Blackwell A, Case LE, Cripe L, Hadjiyannakis S, Olson AK, Sheehan DW, Bolen J, Weber DR, Ward LM, DMD Care Considerations Working Group. Diagnosis and management of Duchenne muscular dystrophy, part 2: respiratory, cardiac, bone health, and orthopaedic management. Lancet Neurol 2018;17:347-361.

18. McNally EM, Kaltman JR, Benson DW, Canter CE, Cripe LH, Duan D, Finder JD, Groh WJ, Hoffman EP, Judge DP, Kertesz N, Kinnett K, Kirsch R, Metzger JM, Pearson GD, Rafael-Fortney JA, Raman SV, Spurney CF, Targum SL, Wagner KR, Markham LW, Working Group of the National Heart, Lung, and Blood Institute; Parent Project Muscular Dystrophy. Contemporary cardiac issues in Duchenne muscular dystrophy. Working Group of the National Heart, Lung, and Blood Institute in collaboration with Parent Project Muscular Dystrophy. Circulation 2015;131:1590-1598.

19. Hicks KA, Tcheng JE, Bozkurt B, Chaitman BR, Cutlip DE, Farb A, Fonarow GC, Jacobs JP, Jaff MR, Lichtman JH, Limacher MC, Mahaffey KW, Mehran R, Nissen
SE, Smith EE, Targum SL, American College of Cardiology; American Heart Association. 2014 ACC/AHA Key data elements and definitions for cardiovascular endpoint events in clinical trials: a report of the American College of Cardiology/American Heart Association Task Force on Clinical Data Standards (Writing Committee to Develop Cardiovascular Endpoints Data Standards). Circulation 2015;132:302-361.

20. Braat E, Hoste L, De Waele L, Gheysens O, Vermeersch P, Goffin K, Pottel H, Goemans N, Levtchenko E. Renal function in children and adolescents with Duchenne muscular dystrophy. Neuromuscul Disord 2015;25:381-387.

21. Hernán MA, Brumback B, Robins JM. Marginal structural models to estimate the causal effect of zidovudine on the survival of HIV-positive men. Epidemiology 2000;11:561-570.

22. Hernán MA, Alonso A, Logan R, Grodstein F, Michels KB, Willett WC, Manson JE, Robins JM. Observational studies analyzed like randomized experiments: an application to postmenopausal hormone therapy and coronary heart disease. Epidemiology 2008;19:766-779.

23. Danaei G, Garcia Rodriguez LA, Cantero OF, Logan R, Hernán MA. Observational data for comparative effectiveness research: an emulation of randomised trials of statins and primary prevention of coronary heart disease. Stat Methods Med Res 2013;22:70-96.

24. Hernán MA, Robins JM. Using big data to emulate a target trial when a randomized trial is not available. Am J Epidemiol 2016;183:758-764.

25. Huitfeldt A, Hernán MA, Kalager M, Robins JM. Comparative effectiveness research using observational data: active comparators to emulate target trials with inactive comparators. EGEMS (Wash DC) 2016;4:20.

26. Garcia-Albeniz $X$, Hsu J, Bretthauer M, Hernán MA. Effectiveness of screening colonoscopy to prevent colorectal cancer among Medicare beneficiaries aged 70 to 79 years: a prospective observational study. Ann Intern Med 2017;166: 18-26.

27. Hernán MA, Sauer BC, Hernandez-Diaz S, Platt R, Shrier I. Specifying a target trial prevents immortal time bias and other self-inflicted injuries in observational analyses. J Clin Epidemiol 2016;79:70-75.

28. Robins JM, Hernán MA, Brumback B. Marginal structural models and causal inference in epidemiology. Epidemiology 2000;11:550-560.

29. Lunceford JK, Davidian M. Stratification and weighting via the propensity score in estimation of causal treatment effects: a comparative study. Stat Med 2004;23: 2937-2960.

30. Eldridge SM, Ashby D, Kerry S. Sample size for cluster randomized trials: effect of coefficient of variation of cluster size and analysis method. Int J Epidemiol 2006; 35:1292-1300.

31. Lin DY, Wei LJ. The robust inference for the Cox proportional hazards model. J Am Stat Assoc 1989;84:1074-1078.

32. Robins JM, Finkelstein DM. Correcting for noncompliance and dependent censoring in an AIDS Clinical Trial with inverse probability of censoring weighted (IPCW) log-rank tests. Biometrics 2000;56:779-788.

33. Rosenbaum PR, Rubin DB. The central role of the propensity score in observational studies for causal effects. Biometrika 1983;70:41-55.

34. Austin PC. Balance diagnostics for comparing the distribution of baseline covariates between treatment groups in propensity-score matched samples. Stat Med 2009;28:3083-3107.

35. Taylor JM, Shen J, Kennedy EH, Wang L, Schaubel DE. Comparison of methods for estimating the effect of salvage therapy in prostate cancer when treatment is given by indication. Stat Med 2014;33:257-274.

36. VanderWeele TJ, Ding P. Sensitivity analysis in observational research: introducing the E-value. Ann Intern Med 2017;167:268-274.

37. Kamdar F, Garry DJ. Dystrophin-deficient cardiomyopathy. J Am Coll Cardiol 2016;67:2533-2546

38. Bourke JP, Bueser T, Quinlivan R. Interventions for preventing and treating cardiac complications in Duchenne and Becker muscular dystrophy and X-linked dilated cardiomyopathy. Cochrane Database Syst Rev 2018;10:CD009068.

39. Cain LE, Robins JM, Lanoy E, Logan R, Costagliola D, Hernán MA. When to start treatment? A systematic approach to the comparison of dynamic regimes using observational data. Int J Biostat 2010;6

40. Hernán MA. How to estimate the effect of treatment duration on survival outcomes using observational data. BM/ 2018;360:k182. 